\title{
Does paracetamol (acetaminophen) reduce the pain of osteoarthritis?: a meta-analysis of randomised controlled trials
}

\author{
W Zhang, A Jones, M Doherty
}

See end of article for authors' affiliations

Correspondence to: Dr W Zhang, Academic Rheumatology, University of Nottingham, Clinical Sciences Building, City Hospital, Nottingham NG5 1PB, UK; weiya.zhang@ nottingham.ac.uk

Accepted 2 February 2004 Published online first 5 March 2004

Objective: To assess the best available evidence for efficacy of paracetamol (acetaminophen) in the treatment of osteoarthritis (OA).

Design: Systematic review and meta-analysis of randomised controlled trials (RCTs).

Data sources: Medline, Embase, Scientific Citation Index, CINAHL, Cochrane Library, and conference abstracts in the past 2 years from the British Society for Rheumatology, the European League Against Rheumatism, the American College of Rheumatology, and the Osteoarthritis Research Society International.

Subjects: 10 RCTs including 1712 patients with either symptomatic OA of the knee (6 trials) or hip/knee (3 trials) or multiple joints (1 trial).

Main outcome measures: (a) effect size (ES) for pain, stiffness, and functional scores from baseline to end point; (b) rate ratio (RR) and number needed to treat for clinical response rate and patient preference for treatment.

Results: Paracetamol was effective in relieving pain due to $\mathrm{OA}$ (ES $=0.21,95 \%$ confidence interval $(\mathrm{Cl})$ 0.02 to 0.41 ). Non-steroidal anti-inflammatory drugs (NSAIDs) were better than paracetamol for pain relief ( $E S=0.20,95 \% \mathrm{Cl} 0.10$ to 0.30 ). Clinical response rate was higher with NSAIDs than with paracetamol $(\mathrm{RR}=1.24,95 \% \mathrm{Cl} 1.08$ to 1.41$)$, and the number of patients who preferred NSAIDs was more than twice the number of those preferring paracetamol ( $R R=2.46,95 \% \mathrm{Cl} 1.51$ to 4.12$)$. NSAIDs were associated with more frequent gastrointestinal discomfort than paracetamol $(R R=1.35,95 \% \mathrm{Cl} 1.05$ to 1.75$)$.

Conclusion: Paracetamol is an effective agent for pain relief due to OA. Although safer, it is less effective than NSAIDs. For safety reasons paracetamol should be the first line treatment, with NSAIDs reserved for those who do not respond.

$\mathrm{P}$ aracetamol (acetaminophen) has been used as an analgesic for over 120 years. Although the exact site and mechanism of action are not clearly defined, paracetamol appears to produce analgesia by raising the pain threshold, predominantly through a central rather than peripheral mechanism. ${ }^{1}$ It has a narrow therapeutic window, but in recommended doses ( $1 \mathrm{~g}$ three to four times daily) is very safe. Its favourable efficacy, excellent safety, widespread availability, and low cost together appear to justify its position as the world market leader for analgesics.

Osteoarthritis (OA) is by far the commonest joint disease. $\mathrm{OA}$ of the knee, the principal large joint to be targeted by OA, results in disabling symptoms in an estimated $10 \%$ of people in the UK older than 55 years, a quarter of whom are severely disabled. ${ }^{2}$ The risk of disability attributable to knee OA alone is as great as that due to cardiac disease and greater than that due to any other medical disorder in the elderly. ${ }^{3}$ Current European evidence based recommendations for the management of knee OA devised by the European League against Rheumatism (EULAR) state that paracetamol is "the oral analgesic to try first and, if successful, the preferred long term oral analgesic" ${ }^{4}{ }^{5}$ However, only one small randomised placebo controlled trial of paracetamol in knee $\mathrm{OA}^{6}$ was found within the period of the EULAR literature review to support this statement. A Cochrane systematic review in $2002^{7}$ similarly found just the one randomised controlled trial $(\mathrm{RCT})^{7}$ to answer the question whether paracetamol is more effective than placebo for OA, but did find RCT evidence for the superiority of non-steroidal anti-inflammatory drugs
(NSAIDs) over paracetamol. However, although some RCTs comparing NSAIDs with paracetamol in OA find that NSAIDs are better, ${ }^{89}$ others report equal efficacy. ${ }^{10-12}$ More recently, the efficacy of paracetamol for knee OA has been seriously questioned by another placebo controlled trial that reported no difference between paracetamol and placebo. ${ }^{13}$ This study comes at a time when the equal efficacy and improved gastrointestinal (GI) safety of coxibs relative to non-selective NSAIDs is being heavily promoted. In America, particularly, confidence in both the efficacy and safety of paracetamol compared with NSAIDs and coxibs has come under challenge. ${ }^{14}$

Therefore we have undertaken a meta-analysis of RCTs including both placebo controlled designs and head to head comparisons of paracetamol with NSAIDs to determine the efficacy of paracetamol in the treatment of OA.

\section{METHODS}

\section{Retrieval of published studies}

Reports of RCTs of paracetamol versus placebo and NSAIDs versus paracetamol were identified through a systematic literature search consisting of:

Abbreviations: ACR, American College of Rheumatology; Cl, confidence interval; ES, effect size; EULAR, European League Against Rheumatism; GI, gastrointestinal; MeSH, medical subject heading; NNT, number needed to treat; NSAIDs, non-steroidal anti-inflammatory drugs; $\mathrm{OA}$, osteoarthritis; RCT, randomised controlled trial; RR, rate ratio; WOMAC, Western Ontario and McMaster Universities OA Index 
Table 1 Literature search and retrieval of relevant randomised controlled trials (RCTs)

\begin{tabular}{lcl}
\hline Stage & $\begin{array}{c}\text { Number } \\
\text { of studies }\end{array}$ & References \\
\hline Raw citations from all sources & 420 & \\
Overlaps/duplications & -97 & \\
Non-RCTs & -294 & \\
RCTs reviewed for inclusion criteria & 29 & $6,8-13,23-44$ \\
Non-placebo and non-NSAID & -5 & $28-32$ \\
comparisons & -12 & $33-44$ \\
Paracetamol combination $v$ & & \\
other agents & -2 & 11,12 \\
Duplicate publications & 10 & $6,8-10,13,23-27$ \\
RCTs met inclusion criteria & 2 & 6,27 \\
Paracetamol $v$ placebo & 2 & 13,25 \\
Paracetamol $v$ NSAIDs $v$ placebo & 6 & $8-10,23,24,26$ \\
Paracetamol $v$ NSAIDs & & \\
\hline
\end{tabular}

- An electronic search of Medline, Embase, CINAHL, the Scientific Citation Index, and the Cochrane Library for the period 1966 to 31 July 2003

- Searches of reference lists of original reports and review articles, retrieved through the electronic searches

- Searches for conference abstracts in the past 2 years via established international societies of rheumatology, such as the British Society for Rheumatology, EULAR, the American College of Rheumatology (ACR), and the Osteoarthritis Research Society International.

The medical subject heading (MeSH) search used in Medline, Embase, and CINAHL consisted of three steps; each contained any possible MeSH relevant to the target condition (OA), study drug (paracetamol), and study method (RCT). All MeSHs were exploded. The three steps were then combined to produce citations associated with RCTs of paracetamol versus placebo and NSAIDs versus paracetamol in the treatment of OA. Keyword search was undertaken in the Scientific Citation Index and Cochrane Library using the words osteoarthritis and paracetamol/acetaminophen. Titles and abstract were reviewed for possible RCTs, and hard copies of the publication were obtained for further scrutiny.

\section{Inclusion and exclusion criteria}

Only RCTs comparing paracetamol with placebo or NSAIDs were included. To facilitate interpretation, only studies undertaken in OA (radiographic evidence or ACR clinical criteria for OA) or pain associated with OA were included. Studies in other conditions such as rheumatoid arthritis, non-OA joint pain, pain due to tooth extraction, surgery, and injury were excluded.

\section{Quality assessment}

The quality of studies was assessed based on randomisation, masking, and withdrawal. ${ }^{15}$ However, we did not allocate any additional score to an RCT according to whether it described the method of randomisation. In our view, this is a feature of the reporting of the trials and allocation of additional points may be arbitrary. A randomised study was defined as one in which the investigators reported it as being randomised without necessarily defining the randomisation method explicitly because in the past this was not a requirement in the reporting of RCTs. Masking was differentiated as double blind, single blind, and open label. Parallel and crossover designs were also categorised. The percentage of withdrawals was calculated. The impact of these quality components for our meta-analysis was assessed by sensitivity analysis.

\section{Data extraction}

Two of us (WZ, AJ) undertook data extraction independently. Any disagreement was resolved by discussion. A customised form was used to record the authors of the study, the year of publication, design of the trial (double blind or single blind, parallel or crossover), location of the trial, length of study, number of subjects, patient age, sex, site of OA (hand, hip, knee, or multiple joints), baseline and end point scores for pain, stiffness, and function, clinical response rate, and patient preference rate. In addition, we recorded the proportion of withdrawals and the number of patients reporting GI discomfort, nausea, headache, and dizziness.

Table 2 Characteristics of randomised controlled trials

\begin{tabular}{|c|c|c|c|c|c|c|c|c|c|c|c|}
\hline \multirow[b]{2}{*}{ Trial } & \multirow[b]{2}{*}{ Design } & \multirow[b]{2}{*}{ OA } & \multirow[b]{2}{*}{ Duration } & \multirow{2}{*}{$\begin{array}{l}\text { Mean age } \\
\text { (range or SD) }\end{array}$} & \multirow{2}{*}{$\begin{array}{l}\text { Male/ } \\
\text { female }\end{array}$} & \multirow[b]{2}{*}{ BPS (\%) } & \multicolumn{2}{|c|}{ Comparison (mg/day) } & \multirow[b]{2}{*}{ n1 } & \multirow[b]{2}{*}{ n2 } & \multirow[b]{2}{*}{ ES (SE) } \\
\hline & & & & & & & Active & Control & & & \\
\hline \multicolumn{12}{|c|}{ Paracetamol v placebo } \\
\hline Amadio $1983^{6}$ & DB-C & Knee & 6 Weeks & $64(43-38)$ & $3 / 22$ & - & Par (4000) & Placebo & 25 & 25 & - \\
\hline Zoppi $1995^{27}$ & $D B-P$ & Hip/knee & 1 Week & $56(20-70)$ & $23 / 37$ & 65 & Par $(3000)$ & Placebo & 30 & 30 & - \\
\hline \multicolumn{12}{|c|}{ NSAIDs $v$ paracetamol $v$ placebo } \\
\hline \multirow[t]{2}{*}{ Case $2003^{13}$} & DB-P & Knee & 12 Weeks & $62(40-75)$ & $41 / 41$ & 34 & Dic (150) & Par $(4000)$ & 25 & 29 & $0.36(0.28)$ \\
\hline & & & & & & & Par (4000) & Placebo & 29 & 28 & $0.09(0.27)$ \\
\hline \multirow[t]{2}{*}{ Pincus $2003^{25}$} & DB-C & Hip/knee & 6 Weeks & 63 & $195 / 329$ & 51 & Cele (200) & Par (4000) & 178 & 168 & $0.14(0.11)$ \\
\hline & & & & & & & Par (4000) & Placebo & 168 & 169 & $0.23(0.11)$ \\
\hline \multicolumn{12}{|c|}{ NSAIDs $v$ paracetamol } \\
\hline \multirow[t]{2}{*}{ Bradley $1991^{10}$} & DP-P & Knee & 4 Weeks & $56(11.6)$ & $47 / 137$ & 50 & Ibu (1200) & Par (4000) & 62 & 61 & $-0.04(0.28)$ \\
\hline & & & & & & & Ibu (2400) & $\operatorname{Par}(4000)$ & 61 & 61 & $0.02(0.18)$ \\
\hline \multirow[t]{3}{*}{ Geba $2002^{23}$} & DB-P & Knee & 6 Weeks & $63(39-91)$ & $121 / 261$ & 60 & $\operatorname{Rof}(12.5)$ & Par (4000) & 96 & 94 & $0.14(0.15)$ \\
\hline & & & & & & & $\operatorname{Rof}(25)$ & Par (4000) & 95 & 94 & $0.46(0.15)$ \\
\hline & & & & & & & Cel (200) & Par (4000) & 97 & 94 & $0.16(0.14)$ \\
\hline March $1994^{8}$ & $\mathrm{n}$ of 1 & Any & 6 Weeks & $64(38-85)$ & $5 / 20$ & - & Dic $(100)$ & Par (2000) & 15 & 15 & $0.31(0.37)$ \\
\hline Pincus $2001^{24}$ & DB-C & Hip/knee & 6 Weeks & $61(19.6)$ & $67 / 160$ & 53 & Dic (150) & $\operatorname{Par}(4000)$ & 112 & 115 & $0.28(0.13)$ \\
\hline Shen $2003^{26}$ & $\mathrm{RCT}$ & Knee & 3 Months & & & - & $\operatorname{Rof}(25)$ & Par (4000) & 10 & 10 & $0.08(0.45)$ \\
\hline Williams $1993^{\circ}$ & DB-P & Knee & 2 Years* & $60(33-85)$ & $44 / 134$ & 53 & Nap (750) & $\operatorname{Par}(2600)$ & 73 & 75 & $0.32(0.17)$ \\
\hline $\begin{array}{l}\text { OA, osteoarthriti } \\
\text { percentage of ba } \\
\text { diclofenac; Cele, } \\
\text { number of patien } \\
{ }^{*} \text { Only } 6 \text { week res } \\
\text { efficacy and side }\end{array}$ & $\begin{array}{l}\text { celecoxib } \\
\text { its in the } \\
\text { sults were } \\
\text { effects. }\end{array}$ & $\begin{array}{l}\text { uble blind } \\
\text { score relati } \\
\text { bu, ibuprof } \\
\text { ntrol group } \\
\text { vailable for }\end{array}$ & $\begin{array}{l}\text {; Rof, rofeco } \\
\text { e primary o }\end{array}$ & me (pain at bas & $\begin{array}{l}\text { llel; RCT, rc } \\
\text { e: } 0 \% \text {, no } \\
\text { ES, effect s } \\
\text { line and en }\end{array}$ & point). Th & $\begin{array}{l}\text { ard error; } n 1 \\
2 \text { year study }\end{array}$ & number of $\mathrm{p}$ & ients & $\begin{array}{l}\text { for bli } \\
\text { ar, par } \\
\text { the tre }\end{array}$ & $\begin{array}{l}\text { ness; BPS (\%), } \\
\text { etamol; Dic, } \\
\text { nent group; n2, } \\
\text { s due to lack of }\end{array}$ \\
\hline
\end{tabular}




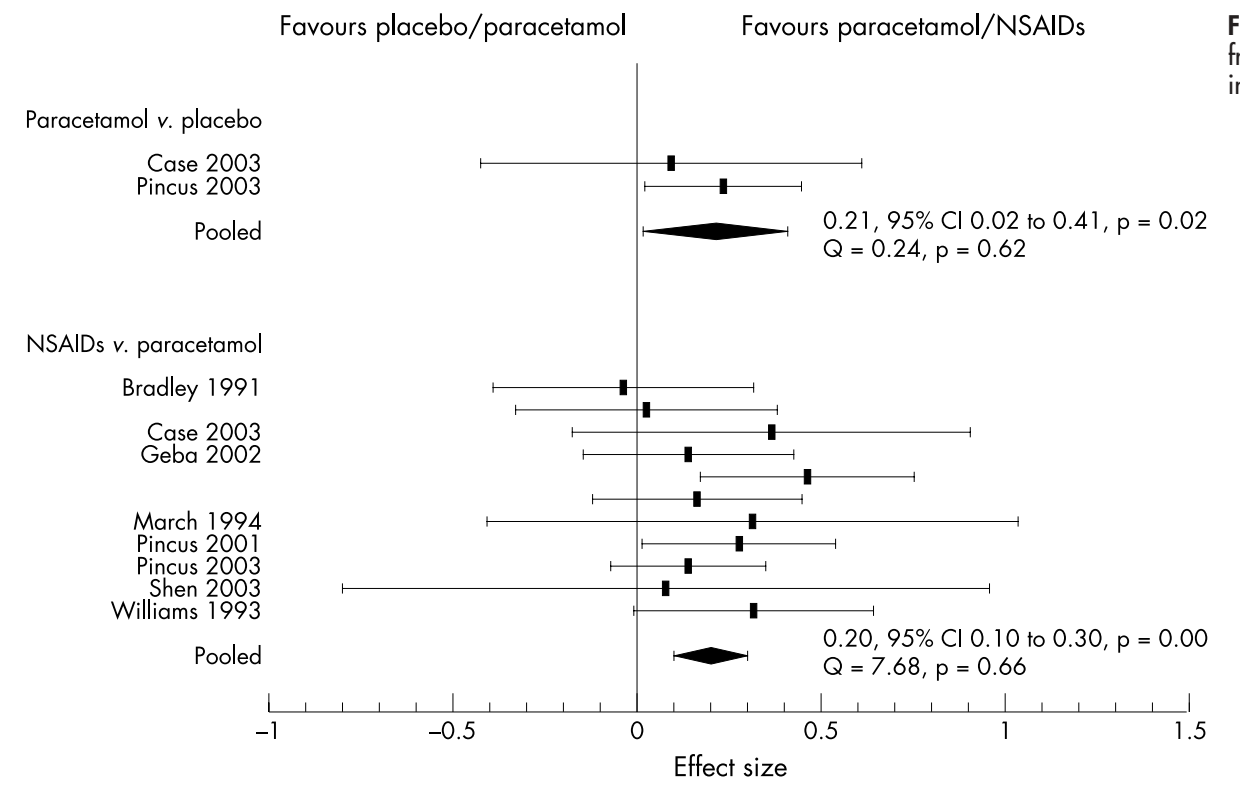

Figure 1 Effect size of pain reduction from baseline and $95 \%$ confidence interval.

\section{Outcome measures}

The primary outcome measure for our analysis was pain reduction from baseline. In addition, we looked at other outcome measures, such as the change in total WOMAC (Western Ontario and McMaster Universities OA Index) ${ }^{16}$ scores, stiffness and functional scores. Clinical response rate and patient preference were also examined. Clinical response rate was defined as the percentage of patients reporting at least moderate to excellent or greater than $50 \%$ pain relief or symptomatic improvement. Patient preference was defined as the proportion of patients preferring the treatment.

\section{Statistical analysis}

We abstracted the mean and standard deviation of the scores for WOMAC, pain, stiffness, and function at baseline and end point from individual studies to calculate the mean reduction and the standard deviation of the reduction. The difference of the reduction and its standard deviation between the interventions was calculated for each individual study. The standard difference or effect size (ES) was then calculated using Hedges unbiased approach. ${ }^{17}$ The weighted pooled ES was estimated using our previously described method. ${ }^{18}$

The rate ratio (RR) was estimated for the dichotomous efficacy data, such as clinical response rate and patient preference. Relative risk was estimated for adverse effect, such as GI discomfort, headache, and dizziness. In all cases, Rothman's method was used for interval estimation of the individual rate ratio or relative risk, ${ }^{19}$ and an intention to treat analysis was used. In the weighted pooling of RR or relative risk, the method of DerSimonian and Laird $^{20}$ was used. The number needed to treat (NNT) and its 95\% confidence intervals (95\% CI) were estimated as described by Cook and Sackett. ${ }^{21}$

A random effects model was used if trials were heterogeneous on the basis of the Q statistic for heterogeneity ${ }^{22}$ and the reason for heterogeneity could not be identified.

\section{RESULTS}

\section{Characteristics of trials}

The literature search based on the search strategies produced 420 citations, including 238 from Embase, 88 from Medline, 14 from CINAHL, 78 from the Scientific Citation Index, and 2 from conference abstracts. After deleting duplications, 323 citations remained for further scrutiny. Of the 323 citations, 29 potential RCTs associated with paracetamol in the treatment of OA were identified. ${ }^{6-13}{ }^{23-44}$ Ten of them met our inclusion, including two placebo controlled trials, ${ }^{6}{ }^{27}$ two placebo and NSAID controlled trials, ${ }^{13}{ }^{25}$ and six head to head (NSAIDs $v$ paracetamol) trials ${ }^{8-10232426}$ (table 1). A search in the Cochrane Library produced 101 hits for OA and

Table 3 Effect sizes of overall WOMAC and other outcome measures

\begin{tabular}{|c|c|c|c|c|}
\hline Outcome improved & No & ES & $95 \% \mathrm{Cl}$ & $\chi_{\text {heter }}^{2}(\mathrm{df})$ \\
\hline \multicolumn{5}{|l|}{ Paracetamol v placebo } \\
\hline WOMAC & 2 & 0.14 & -0.06 to 0.34 & $1.20(1)$ \\
\hline Pain & 2 & 0.21 & 0.02 to $0.41^{*}$ & 0.24 (1) \\
\hline \multicolumn{5}{|l|}{ NSAIDs v placebo } \\
\hline WOMAC & 2 & 0.34 & 0.14 to $0.54^{* *}$ & $0.04(1)$ \\
\hline Pain & 2 & 0.34 & 0.14 to $0.54^{* *}$ & $0.53(1)$ \\
\hline \multicolumn{5}{|c|}{ NSAIDs v paracetamol } \\
\hline WOMAC & 4 & 0.30 & 0.17 to $0.44^{* *}$ & $5.43(3)$ \\
\hline Pain & 11 & 0.20 & 0.10 to $0.30^{* *}$ & $7.68(10)$ \\
\hline Stiffness & 5 & 0.34 & 0.19 to $0.50^{* *}$ & 5.51 (4) \\
\hline Function & 6 & 0.22 & 0.08 to $0.35^{* *}$ & $7.37(5)$ \\
\hline
\end{tabular}

${ }^{*} \mathrm{p} \leqslant 0.05 ;{ }^{* *} \mathrm{p} \leqslant 0.01$; No, number of comparisons; $\mathrm{ES}$, effect size; Cl, confidence interval; $\chi^{2}$ heter $(\mathrm{df}), \chi^{2}$ for heterogeneity (degree of freedom). 


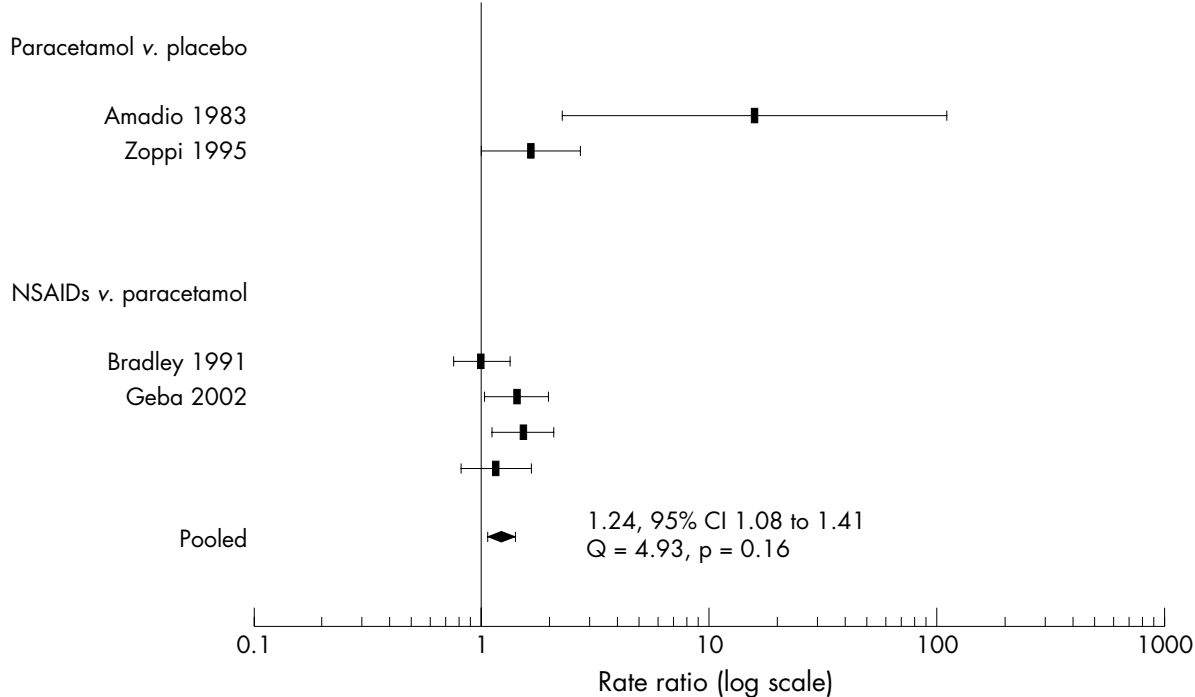

paracetamol, including 17 systematic reviews and 84 registered clinical trials. These were scrutinised but no additional trials were identified.

The RCTs included were mainly undertaken in the United States except for one in the $\mathrm{UK}^{9}$ and another in Italy. ${ }^{27}$ They were stated to be RCTs, but no further details of random allocation (for example, allocation sequence and concealment) were given, including those ${ }^{1323-26}$ published after the CONSORT statement. ${ }^{45}$ Of these RCTs, five were double blind parallel studies ${ }^{9} 10^{13} 2327$; three were double blind crossover studies ${ }^{624}$; one used an "n of $\mathrm{l}^{\text {" }}$ design ${ }^{8}$; and one RCT gave no further definition of blindness (abstract only available) ${ }^{26}$ (table 2). Withdrawals varied from $0 \%$ to $40 \%$.

Of the 10 trials, six were conducted in patients with knee OA, three included subjects with hip and knee OA, and one was undertaken in patients with OA at any joint (single or multiple joints affected). Before entry to the trials, patients were asked to stop any previous treatments for OA symptoms and some had 2-7 week pre-washout periods. ${ }^{610132425}$ Except for one study, ${ }^{13}$ patient baseline pain severity was $50-65 \%$ (table 2), and no trial had a requirement for a worsening pain score after stopping previous treatments. The median length of study was 6 weeks (range 1 week to 2 years). For the 2 year study, ${ }^{9}$ only 6 week efficacy data were available to derive the primary outcome - that is, pain score at baseline and end point. The follow up period up to 2 years mainly looked at the number of patients withdrawn and reasons for withdrawal. Of the 10 trials, 7 used a fixed dose of paracetamol $4000 \mathrm{mg}$ a day and 3 used 2000, 2600, and $3000 \mathrm{mg}$ a day, respectively (table 2). Doses of NSAIDs varied according to the individual drug and their usual dosage. Mean ages were relatively young and ranged from 55 to 64 years. All but one study included more women than men. Pain was used as the primary outcome for efficacy in all studies and was measured by either the WOMAC pain scale or a single visual analogue $0-100 \mathrm{~mm}$ scale. Where available, baseline and end point pain scores were abstracted for further analysis (table 2).

\section{Efficacy}

Pain reduction

Figure 1 shows the ES in pain reduction with paracetamol versus placebo, and NSAIDs versus paracetamol are also shown. Two placebo controlled trials ${ }^{1325}$ provided pain intensity at both baseline and end point. Analgesic effect was therefore estimated using pain reduction from baseline. Of these two trials, one demonstrated that paracetamol was no better than placebo, whereas the other showed that

Table 4 Comparison of risk of side effects (95\% confidence intervals) with paracetamol versus placebo, and NSAIDs versus paracetamol

\begin{tabular}{|c|c|c|c|c|}
\hline Comparisons & GI discomfort & Nausea & Headache & Dizziness \\
\hline \multicolumn{5}{|l|}{ Paracetamol v placebo } \\
\hline Crude rate & $5 / 55 \vee 6 / 55$ & $1 / 25 \vee 0 / 25$ & $2 / 55 \vee 2 / 55$ & $1 / 55 \vee 7 / 55$ \\
\hline Weighted relative risk & $0.80(0.27$ to 2.37$)$ & $3.00(0.13$ to 70.30$)$ & $1.06(0.16$ to 6.95$)$ & $0.36(0.04$ to 2.96$)$ \\
\hline \multicolumn{5}{|c|}{ NSAIDs overall v paracetamol } \\
\hline Crude rate & $108 / 704$ v 82/702 & $29 / 491$ v 23/492 & $27 / 581 \vee 32 / 580$ & $5 / 288 \vee 3 / 282$ \\
\hline Weighted relative risk & $1.35(1.05 \text { to } 1.75)^{*}$ & $1.26(0.73$ to 2.18$)$ & $0.85(0.52$ to 1.40$)$ & $1.57(0.36$ to 6.85$)$ \\
\hline \multicolumn{5}{|c|}{ Conventional NSAIDs v paracetamol } \\
\hline Crude rate & $105 / 416$ v $76 / 420$ & $15 / 203$ v $8 / 210$ & $5 / 293 \vee 8 / 298$ & - \\
\hline Weighted relative risk & $1.39(1.07 \text { to } 1.80)^{*}$ & $1.94(0.84$ to 4.48$)$ & $0.67(0.23$ to 1.96$)$ & - \\
\hline \multicolumn{5}{|l|}{ Coxibs v paracetamol } \\
\hline Crude rate & $3 / 288$ v $6 / 282$ & $14 / 288$ v $15 / 282$ & $22 / 288$ v $24 / 282$ & $5 / 288 \vee 3 / 282$ \\
\hline Weighted relative risk & 0.65 (0.17 to 2.52$)$ & 0.92 (0.45 to 1.89$)$ & 0.91 (0.52 to 1.60$)$ & $1.57(0.36$ to 6.85$)$ \\
\hline
\end{tabular}




\begin{tabular}{|c|c|c|}
\hline \multirow[b]{2}{*}{ Quality of study } & \multicolumn{2}{|c|}{ ES of pain reduction and $95 \% \mathrm{Cl}$} \\
\hline & $\begin{array}{l}\text { Paracetamol } v \\
\text { placebo }\end{array}$ & $\begin{array}{l}\text { NSAIDs } v \\
\text { paracetamol }\end{array}$ \\
\hline $\begin{array}{l}\text { Study design } \\
\text { Double blind parallel } \\
\text { Double blind crossover } \\
\text { Others }\end{array}$ & $\begin{array}{l}0.09(-0.43 \text { to } 0.61) \\
0.23(0.02 \text { to } 0.44)^{*} \\
-\end{array}$ & $\begin{array}{l}0.20(0.08 \text { to } 0.33)^{*} \\
0.19(0.03 \text { to } 0.36)^{*} \\
0.22(-0.34 \text { to } 0.78)\end{array}$ \\
\hline $\begin{array}{l}\text { Withdrawal rate } \\
<10 \% \\
\geqslant 10 \%\end{array}$ & $0.21(0.02 \text { to } 0.41)^{*}$ & $\begin{array}{l}0.17(0.05 \text { to } 0.31)^{*} \\
0.22(0.09 \text { to } 0.36)^{* *}\end{array}$ \\
\hline
\end{tabular}

paracetamol was significantly better than placebo. The pooled ES was 0.21 (95\% CI 0.02 to $0.41, p=0.02)$. Eight head to head comparisons of NSAIDs versus paracetamol were analysed. Although some of these showed that NSAIDs were better than paracetamol, others demonstrated equal reductions in pain for both agents. Nevertheless, the pooled ES was 0.20 (95\% CI 0.10 to $0.30, p=0.000)$, indicating that NSAIDs are better than paracetamol in relieving pain due to OA (fig l).

\section{Overall WOMAC}

Two placebo controlled trials ${ }^{1325}$ provided overall WOMAC scores. Both showed no statistically significant difference between paracetamol and placebo (pooled ES $=0.14,95 \%$ CI -0.06 to 0.34 ) (table 3 ). In contrast, NSAIDs were significantly better than placebo (pooled $\mathrm{ES}=0.34,95 \% \mathrm{CI}$ 0.14 to 0.54 ) or paracetamol (pooled ES $=0.3,95 \%$ CI 0.17 to 0.44) (table 3).

\section{Clinical response rate and patients' preference} Two placebo controlled trials ${ }^{627}$ were available for this outcome measure (fig 2). Both trials showed that paracetamol was better than placebo, but the results were heterogeneous $(\mathrm{Q}=4.93 ; \mathrm{p}=0.03)$. Clinical response $\mathrm{RRs}$ were $16(95 \%$ CI 2.32 to $110.45 ; p=0.02)$ and $1.67(95 \%$ CI 1.00 to $2.76 ; \mathrm{p}=0.05)$, respectively. In contrast, the trials comparing NSAIDs and paracetamol were homogeneous. The results showed that NSAIDs were statistically better than paracetamol. The pooled clinical response RR was 1.24 (95\% CI 1.08 to $1.41, p=0.001)$. The NNT was $8(95 \%$ CI 5 to 19 , $\mathrm{p}<0.001)$ - that is, eight patients needed to be treated before one drug (NSAID) shows clear benefit over the other (paracetamol), as judged by moderate to excellent pain relief.

Three trials ${ }^{2425}$ also examined patient preference for NSAIDs or paracetamol when both treatments were taken in turn in either a crossover design ${ }^{24}{ }^{25}$ or an $\mathrm{n}$ of 1 design. ${ }^{8}$ The results showed that more patients preferred NSAIDs $(61 \%)$ than paracetamol $(20 \%)$. The pooled RR was 2.46 (95\% CI 1.51 to $4.12, \mathrm{p}<0.001$ ) and the NNT was 3 (95\% CI 2 to 7 , $\mathrm{p}<0.001$ ) - that is, on average, treating three patients would lead to one patient preferring NSAIDs rather than paracetamol. The results were homogeneous irrespective of paracetamol doses of $2 \mathrm{~g}$ and $4 \mathrm{~g}$ daily. The percentage of patients preferring paracetamol was similar to that preferring neither treatment (18\%). The pooled RR was 0.96 (95\% CI 0.79 to 1.32 ).

\section{Side effects}

Comparison of side effects showed that paracetamol had a similar safety profile to that of placebo, whereas NSAIDs caused more GI discomfort (defined as any of the following GI events: abdominal pain, GI distress, nausea, vomiting, dyspepsia, or diarrhoea) than paracetamol. The relative risk of GI discomfort with NSAIDs compared with paracetamol was 1.35 (95\% CI 1.05 to 1.75 ) (table 4). Breakdown of NSAIDs into conventional NSAIDs and coxibs provided further detail of this difference: while the conventional NSAIDs had a higher risk of GI discomfort $(\mathrm{RR}=1.39,95 \%$ CI 1.07 to 1.80$)$, coxibs had a similar risk to paracetamol ( $\mathrm{RR}=0.65,95 \%$ CI 0.17 to 2.52$)$.

\section{Sensitivity analyses}

Sensitivity analyses were undertaken to determine whether the quality of trials influences the results. Trials designed as double blind parallel, double blind crossover, and other designs such as $\mathrm{n}$ of 1 and RCT with no further information about "blindness" were stratified and the ES of pain reduction and 95\% CIs were compared. There were no statistically significant differences between strata (95\% CIs overlapped), although the stratification did sometimes affect significance levels within each stratum. For example, although double blind parallel and crossover designs produced statistically significant ES, and other designs produced non-statistically significant ES, there was no statistically significant difference among the three designs, as their $95 \%$ CIs overlapped (table 5). In addition, we divided the studies into two strata according to withdrawal rate $(<10 \%$ and $\geqslant 10 \%)$. The results showed that the ES were not statistically different between the two strata (table 5).

\section{DISCUSSION}

This is the first comprehensive systematic literature review of RCTs of paracetamol in the treatment of OA. Compared with the recent Cochrane review, ${ }^{7}$ three more placebo controlled RCTs have been retrieved, ${ }^{1325} 27$ providing evaluation of significantly more RCT evidence in OA for this widely used analgesic. Our meta-analysis confirms that paracetamol is effective in relieving pain due to OA. The ES of 0.21 is small according to Cohen's definition ${ }^{46}$ but is statistically significant. We also calculated the clinical response rate and showed that paracetamol has a higher response rate than placebo. However, because the definitions of this outcome may be different for different trials - that is, either moderate to excellent pain relief or clinical symptom improvement, the results are heterogeneous and not relevant for pooling. The analysis does not show any statistically significant difference between paracetamol and placebo for other outcomes such as overall WOMAC score, supporting the construct that paracetamol is a simple analgesic rather than an anti-inflammatory agent and may have limited effects on other aspects of OA symptomatology.

Unlike paracetamol, NSAIDs relieve not just pain due to OA but affect other outcomes such as total WOMAC, stiffness, and physical function. Patients obtain better pain relief with NSAIDs than with paracetamol. The ES is 0.20 , similar to that obtained by comparing paracetamol with placebo. In addition, the clinical response rate is higher with NSAIDs than with paracetamol and more patients prefer NSAIDs than paracetamol in the short term. However, paracetamol does appear to be better tolerated, with a side effect profile similar to that of placebo. In contrast, NSAIDs are associated with significantly increased rates of GI discomfort. A meta-analysis of 16 clinical trials, 23 casecontrol, and 9 cohort studies provides even more compelling evidence for the increased rate of GI side effects of NSAIDs. ${ }^{47}$ However, more information about the long term relative safety and tolerability of NSAIDs and paracetamol is required.

The safety of paracetamol at currently recommended doses has been challenged by two recent studies that suggest a dose dependent increased risk of GI bleeding. One is a case-control 
study using an automated UK database ${ }^{48}$ and the other a retrospective cohort analysis from Canada. ${ }^{49}$ However, both studies contain major confounding factors, and one $e^{49}$ found an increased risk of dyspepsia but not serious GI events. Both are contrary to a large body of epidemiological evidence showing no GI risk from paracetamol, ${ }^{14}{ }^{50}$ including a metaanalysis based on individual patient data derived from contemporaneous case-control studies examining serious upper GI bleeding. ${ }^{50}$ Although not directly examining safety, our analysis indicates that paracetamol is safe in treatment doses of up to $4 \mathrm{~g}$ daily from 1 week to 2 years, at least in an RCT. However, the GI discomfort in this review is defined as any GI events, such as abdominal pain, GI distress, nausea, vomiting, or dyspepsia. These are different from the serious GI events such as GI bleeding or other GI ulcer complications, which cannot be determined in this group of short term randomised controlled trials without endoscopic assessment. Several short term ( $<7$ days) endoscopic trials have been undertaken to investigate the effects of paracetamol, NSAIDs, and/or placebo for these outcomes in healthy volunteers. ${ }^{51-53}$ None of them demonstrate that the GI toxicity of paracetamol exceeds that of placebo, though the toxicity of NSAIDs clearly does. However, there is no trial evidence to confirm the longer term (for example, 3 months and over) GI safety of paracetamol. Also, we still do not know whether it is more toxic to the population at high risk, such as the elderly with OA. Further well designed long term studies in patients with OA may be helpful to ascertain the risk.

The analysis has some limitations. Firstly, like many other systematic reviews, we were unable to retrieve unpublished trials so that publication bias may be a factor. Secondly, we included studies published only in abstract form, which are incomplete reports, and we were unable to assess fully the quality of these studies. This may cause information bias. Thirdly, in converting outcome measures, particularly for clinical response rate, the variation of the outcome definitions from study to study may affect the results. We therefore could not pool the results if there was any heterogeneity among the trials for these outcome measures. This is why we chose ES as our primary outcome measure because it neglects the different scales and presents a standardised difference between two groups. A caveat to many studies of $\mathrm{OA}$ is that most trials are only short term and more long term efficacy studies are required in a condition that causes long term pain and disability.

In conclusion, this analysis confirms that paracetamol is effective in relieving the pain of large joint OA. NSAIDs have a higher ES than paracetamol for pain relief and in addition help other symptoms of OA such as stiffness. However, weighed against this relative difference in efficacy is the excellent safety record of paracetamol. The selection of treatments depends on a balance of factors, of which efficacy is just one. Other factors include safety, tolerability, availability, cost, and patient acceptance. ${ }^{44}$ However, given its favourable safety profile within the treatment dose of up to $4 \mathrm{~g}$ a day, this largest meta-analysis of paracetamol confirms significant efficacy for pain relief in OA. It therefore supports the recommendation that paracetamol be considered the first line oral analgesic in the management of $\mathrm{OA}^{4}{ }^{5}$

\section{ACKNOWLEDGEMENT}

Funding: Arthritis Research Campaign: D0565, D0593.

\section{Authors' affiliations}

W Zhang, M Doherty, Academic Rheumatology, University of Nottingham, Clinical Sciences Building, City Hospital, Nottingham NG5 1PB, UK

A Jones, Rheumatology Unit, Nottingham City Hospital, Nottingham NG5 1PB, UK

\section{REFERENCES}

1 Raffa RB, Stone DJ, Tallarida RJ. Unexpected and pronounced antinociceptive synergy between spinal acetaminophen (paracetamol) and phentolamine. Eur J Pharmacol 2001;412:R1-2.

2 Peat G, McCarney R, Croft P. Knee pain and osteoarthritis in older adults: a review of community burden and current use of primary health care. Ann Rheum Dis 2001;60:91-7.

3 Guccione AA, Felson DT, Anderson JJ, Anthony JM, Zhang Y, Wilson PW, et al. The effects of specific medical conditions on the functional limitations of elders in the Framingham study. Am J Public Health 1994;84:351-8.

4 Pendleton A, Arden N, Dougados M, Doherty M, Bannwarth B, Bijlsma JWJ, et al. EULAR recommendations for the management of knee osteoarthritis: report of a task force of the Standing Committee for International Clinical Studies Including Therapeutics Trials (ESCISIT). Ann Rheum Dis 2000;59:936-44.

5 Jordan K, Arden N, Doherty M, Bannworth B, Bijlsma JWJ, Dieppe P, et al. EULAR Recommendations 2003: an evidence based approach to the management of knee osteoarthritis. Ann Rheum Dis 2003;62:1 145-55.

6 Amadio P Jr, Cummings DM. Evaluation of acetaminophen in the management of osteoarthritis of the knee. Curr Ther Res 1983;34:59-66.

7 Towheed TE, Judd MJ, Hochberg MC, Wells G. Acetaminophen for osteoarthritis (Cochrane Review). In: The Cochrane Library, Issue 2. Oxford: Update Software, 2003.

8 March L, Irwig L, Schwarz J, Simpson J, Chock C, Brooks P. n of 1 trials comparing a non-steroidal anti-inflammatory drug with paracetamol in osteoarthritis. BMJ 1994;309:1041-5, discussion 1045-6.

9 Williams HJ, Ward JR, Egger MJ, Neuner R, Brooks RH, Clegg DO, et al. Comparison of naproxen and acetaminophen in a two-year study of treatment of osteoarthritis of the knee.[comment]. Arthritis Rheum 1993;36:1196-206.

10 Bradley JD, Brandt KD, Katz BP, Kalasinski LA, Ryan SI. Comparison of an antiinflammatory dose of ibuprofen, an analgesic dose of ibuprofen, and acetaminophen in the treatment of patients with osteoarthritis of the knee. N Engl J Med 1991;325:87-91.

11 Bradley JD, Brandt KD, Katz BP, Kalasinski LA, Ryan SI. Treatment of knee osteoarthritis: relationship of clinical features of joint inflammation to the response to a nonsteroidal antiinflammatory drug or pure analgesic. $J$ Rheumatol 1992;19:1950-4.

12 Bradley JD, Katz BP, Brandt KD. Severity of knee pain does not predict a better response to an antiinflammatory dose of ibuprofen than to analgesic therapy in patients with osteoarthritis.[comment]. J Rheumatol 2001;28:1073-6.

13 Case JP, Baliunas AJ, Block JA. Lack of efficacy of acetaminophen in treating symptomatic knee osteoarthritis: a randomized, double-blind, placebocontrolled comparison trial with diclofenac sodium. Arch Intern Med 2003; 163: 169-78.

14 Abramson SA. Et tu acetaminophen? Arthritis Rheum 2002;46:2831-5.

15 Jadad AR, Moore RA, Carroll D, Jenkinson C, Reynolds DJ, Gavaghan DJ, et al. Assessing the quality of randomised clinical trials: is blinding necessary: Control Clin Trials 1996;17:1-12.

16 Bellamy N, Buchanan WW, Goldsmith CH, Cambell J, Stitt L. Validation of WOMAC. J Orthop Rheum 1988;1:95-108.

17 Hedges LV. Fitting continues models to effect size data. J Edu Stat 1982;7:245-70.

18 Zhang WY, Li Wan Po A, Analgesic efficacy of paracetamol and of its combination with codeine and caffeine in surgical pain-a meta-analysis. $J$ Clin Pharmacy Ther 1996;21:261-82.

19 Rothman KJ. Modern epidemiology. Boston: Little, Brown, and Company, 1986:177-233.

20 DerSimonian R, Laird N. Meta-analysis in clinical trials. Control Clin Trials 1986;7:177-88.

21 Cook RJ, Sackett DL. The number needed to treat: a clinically useful measure of treatment effect. BMJ 1995;320:452-4.

22 Whitehead A, Whitehead J. A general parametric approach to the metaanalysis of randomised clinical trials. Stat Med 1991;10:1665-77.

23 Geba GP, Weaver AL, Polis AB, Dixon ME, Schnitzer TJ, Vioxx ACT (VACT) Group. Efficacy of rofecoxib, celecoxib, and acetaminophen in osteoarthritis of the knee: a randomized trial. JAMA 2002;287:64-71.

24 Pincus T, Koch GG, Sokka T, Lefkowith J, Wolfe F, Jordan JM, et al. A randomized, double-blind, crossover clinical trial of diclofenac plus misoprostol versus acetaminophen in patients with osteoarthritis of the hip or knee[comment]. Arthritis Rheum 2001;44:1587-98.

25 Pincus T, Fort JF, Mangal B, Koch G, Wolfe F, Moskowitz R, et al. Patients preference for placebo, acetaminophen (paracetamol), or celecoxib effectiveness study (PACES-1): a double-blinded, randomised, cross-over clinical trial in patients with osteoarthritis of the hip or knee [abstract]. Ann Rheum Dis 2003;62(suppl I):73.

26 Shen H, Sprott H, Aeschlimann A, Gay R, Uebelhart D, Michel BA, et al. Primary analgesic action of acetaminophen and rofecoxib in osteoarthritis [abstract]. Ann Rheum Dis 2003;62(suppl I):258.

27 Zoppi M, Peretti G, Boccard E. Placebo-controlled study of the analgesic efficacy of an effervescent formulation of $500 \mathrm{mg}$ paracetamol in arthritis of the knee or the hip. European Journal of Pain 1995;16:42-8.

28 Amor B, Benarrosh C. A method for comparing analgesics: glafenine and paracetamol. Multicenter cross-over approach. Clin Rheumatol 1988;7:492-7

29 Bacon TH, Hole JG, North M, Burnett I. Analgesic efficacy of sustained release paracetamol in patients with osteoarthritis of the knee. Br J Clin Pharmacol 2002; 53:629-36

30 Decousus H, Laporte S, Perpoint B, Mismetti P, Hocquart JL, et al. Comparison in 141 outpatients with osteoarthritis of 2 combinations of paracetamol with a 
narcotic analgesic-a controlled clinical-trial. European Journal of Pharmacology 1990; 183:1044

31 Erturk H, Celiker R, Aydin M, Ugur O. Comparison of efficacy and tolerability of acemetacin and acetaminophen in the treatment of knee osteoarthritis. Journal of Rheumatology and Medical Rehabilitation 1998;9:157-61.

32 Lequesne M, Fannius J, Reginster JY, Verdickt W, du Laurier MV. Floctafenin versus acetaminophen for pain control in patients with osteoarthritis in the lower limbs. Franco-Belgian Task Force. Rev Rhum Engl Ed 1997;64:327-33.

33 Boissier C, Perpoint B, Laporte-Simitsidis S, Mismetti P, Hocquart J, Gayet JL, et al. Acceptability and efficacy of two associations of paracetamol with a central analgesic (dextropropoxyphene or codeine): comparison in osteoarthritis. J Clin Pharmacol 1992;32:990-5.

34 Caldwell JR, Hale ME, Boyd RE, Hague JM, Iwan T, Shi M, et al. Treatment of osteoarthritis pain with controlled release oxycodone or fixed combination oxycodone plus acetaminophen added to nonsteroidal antiinflammatory drugs: a double blind, randomized, multicenter, placebo controlled trial. $J$ Rheumatol 1999;26:862-9.

35 Glowinski J, Boccard E. Placebo-controlled study of the analgesic efficacy of a paracetamol $500 \mathrm{mg} /$ codeine $30 \mathrm{mg}$ combination together with low- dose vs high-dose diclofenac in rheumatoid arthritis. Clinical Drug Investigation 1999; 18:189-97.

36 Innes EH. Osteoarthritis in elderly patients - a comparison of benorylate (Benoral) with an aspirin-paracetamol mixture. Clinical Trials Journal 1982;19:179-83

37 Kjaersgaard-Andersen P, Nafei A, Skov O, Madsen F, Andersen HM, Kroner $\mathrm{K}$, et al. Codeine plus paracetamol versus paracetamol in longer-term treatment of chronic pain due to osteoarthritis of the hip - a randomized, double-blind, multicenter study. Pain 1990;43:309-18.

38 Kuntz D, Brossel R. Analgesic effect and clinical tolerance of paracetamol $500 \mathrm{mg}$ plus cafeine $50 \mathrm{mg}$ versus paracetamol $400 \mathrm{mg}$ plus dextropropoxyphen $30 \mathrm{mg}$ for back pain. Presse Med 1996;25:1171-4.

39 Maneksha S. 'Safapryn' and benorylate-a comparative trial of two new preparations of aspirin and paracetamol in the treatment of rheumatoid arthritis and osteoarthritis. Curr Med Res Opin 1973;1:563-8.

40 Matts SG, Boston PF. Paracetamol plus metoclopramide ('Paramax') as an adjunct analgesic in the treatment of arthritis. Curr Med Res Opin 1983:8:547-52.

41 Seideman P, Samuelson P, Neander G. Naproxen and paracetamol compared with naproxen only in coxarthrosis. Increased effect of the combination in 18 patients. Acta Ortho Scand 1993;64:285-8.

42 Silverfield JC, Kamin M, Wu SC, Rosenthal N. CAPSS-105 Study Group.

Tramadol/acetaminophen combination tablets for the treatment of osteoarthritis flare pain: a multicenter, outpatient, randomized, double-blind, placebo-controlled, parallel-group, add-on study. Clin Ther 2002;24:282-97.

43 Vignon E, Bannwarth B, Conrozier T, Derobert E, Verdoncq B. Multicenter, double-blind, clinical trial comparing two tablets bid to one tablet qid of the same acetaminophen-dextropropoxyphen-caffeine combination in patients with osteoarthritis. Semaine Des Hopitaux 1999;75:419-25.

44 Vlok GJ, van Vuren JP. Comparison of a standard ibuprofen treatment regimen with a new ibuprofen/paracetamol/codeine combination in chronic osteo-arthritis. S Afr Med J 1987; (suppl 1):4-6.

45 Begg CB, Cho MK, Eastwood S, Horton R, Moher D, Olkin I, et al. Improving the quality of reporting of randomized controlled trials: the CONSORT statement. JAMA 1996;276:637-9.

46 Cohen J. Statistical power analysis for behavioural sciences. New York: Academic Press, 1977.

47 Ofman JJ, MacLean CH, Straus WL, Morton SC, Berger ML, Roth EA, et al. A metaanalysis of severe upper gastrointestinal complications of nonsteroidal antiinflammatory drugs. J Rheumatol 2002;29:804-12.

48 Garcia Rodriquez LA, Hernandez-Diaz S. Relative risk of upper gastrointestinal complications among users of acetaminophen and nonsteroidal anti-inflammatory drugs. Epidemiology 2001;12:570-6

49 Rahme E, Pettitt $D$, LeLorier J. Determinants and sequelae associated with utilization of acetaminophen versus traditional nonsteroidal antiinflammatory drugs in an elderly population. Arthritis Rheum 2002;46:3046-54.

50 Lewis SC, Langman MJS, Laporte J, Matthews JNS, Rawlins MD, Wiholm B. Dose-response relationships between individual nonasprin nonsteroidal antiinflammatory drugs (NSAIDs) and serious upper gastrointestinal bleeding: a meta-analysis based on individual patient data. $\mathrm{Br} J \mathrm{Clin}$ Pharmacol 2002;54:320-6.

51 Lanza FL, Codispoti JR, Nelson EB. An endoscopic comparison of gastroduodenal injury with over-the-counter doses of ketoprofen and acetaminophen. Am J Gastroenteral 1998:93:1051-4.

52 Muller P, Simon B, Weise D, Dammann HG. Endoscopic studies on the gastric tolerance of paracetamol and acetylsalicylic acid: a placebo-controlled, double-blind study in healthy volunteers. Arzneimittelforschung 2000;40:316-18.

53 Jerussi TP, Caubet JF, McCray JE, Handley DA. Clinical endoscopic evaluation of the gastroduodenal tolerance to (R)-ketoprofen, (R)-flurbiprofen, racemic ketoprofen, and paracetamol: a randomised, single-blind, placebo-controlled trials. J Clin Pharmacol 1998;38(suppl): 19-24S.

54 Courtney P, Doherty M. Key questions concerning paracetamol and NSAIDs for osteoarthritis. Ann Rheum Dis 2002;61:767-73. 